\title{
The Perception of Access in Sydney
}

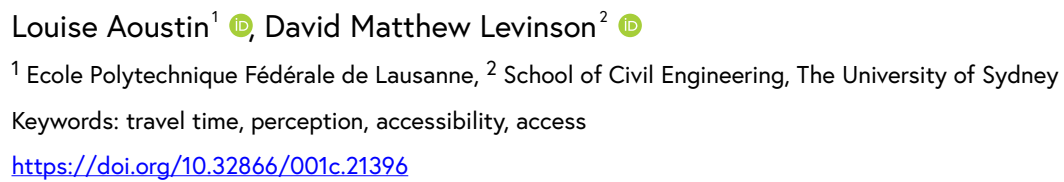

Findings

Based on a survey of 197 Sydneysiders, this study shows residents overestimated the attractiveness of the city centre compared to the entire metropolitan area, as well as the number of jobs they can reach from home. They also overestimated travel times compared to Google Maps, especially for travel times by car.

\section{Questions}

Access was defined by Hansen as a measurement of the spatial distribution of activities about a point, adjusted for the ability and the desire of people or firms to overcome spatial separation (1959). This adjustment is essential in measuring access. Indeed, if we only consider the standard access based on urban characteristics, we suppose a rational reflection before each individual's journey, as if he knew all the costs and benefits of all the different alternatives. However, decision making in transport is a much more complex mechanism and depends not only on the urban characteristics, but also on the perception the user have of these characteristics. This perception creates a unique mental map for every transport user (Lynch 1960), on which he relies to make his transport choices. Therefore, we also need to consider the perception of access to understand the modal choices of the inhabitants. We pose the following hypothesis:

1. Estimates of jobs in the City of Sydney will be too high. The central city tends to have over-inflated importance in people's perception of the regional job market due to its high visibility and landmark status. Most Sydneysiders will be familiar with the CBD as well as their own neighborhood, but less familiar with other parts of the city.

2. People living nearer the City of Sydney tend to overestimate its attractiveness compared to those farther from the City. Because they are more likely to use the City on a regular basis, we expect people who reside closer to the CBD will exaggerate its size in their mental calculations.

3. Cycling access to work is under-estimated compared to the access by public transport. The importance of public transport, like the importance of the CBD, comes from its particular use case. Because fewer people bicycle, they will be least informed about the nature of cycling. 
4. People overestimate travel times for transport modes they do not use. We believe people will better estimate modes they do use, and have a selection bias, so that they will naturally favor what they engage in.

5. Public transport users have the least accurate perception of travel times for the transport mode they do not use. We believe this because they have the least control over their travel, being passengers, and having the least direct route, thus the weakest perception of the actual environment.

\section{Methods}

The data used were collected through an online survey using mostly social media. It was conducted from April 2nd 2020 to May 1st 2020, and consisted of five parts. In this study, we will only use parts 1, $2 \& 5$ (Aoustin 2020).

The characteristics of the sample are presented in table 1 . They are compared to the characteristics of Sydney's most densely populated neighborhoods, as 77\% of the respondents live in the latter. The densely populated area is characterized by Australian Bureau of Statistics' Statistical Area Level 2 (SA2) with a population density greater than 3,000 inhabitants per square kilometer. (There are 2,310 SA2 regions in Australia, with an average population of about 10,000.) However, high density SA2s which are isolated are excluded, and SA2s with a lower density but which were surrounded by high density SA2 are included. This is done in order to ensure a contiguous area (see figure 1).

The sample we obtained is slightly younger than the actual population, with $1 / 3$ of the respondents between 20 and 29 years old. Almost all (94\%) are either workers, students or both. The income is also high, with $45 \%$ of the respondents earning $\$ 2500$ or more per week per household. The transport mode used by the respondents also differs from the general population - we over-sampled bicyclists, so $34 \%$ of the sample commute by push bike or Ebike, while only $1 \%$ of the population actually uses this transport mode to commute to work. Bike users indeed had active communities on social media that were easy to reach, and bicyclists, it would appear, are keen to talk about their travel. We also have over-sampled public transport users, and car users are under-represented, as we have only $10 \%$ of drivers. Since we stratify the analysis by mode, the modal use weightings are not critical.

To assess the perception of access to jobs, respondents were first asked to estimate the number of people who work in the Greater Sydney Area and in the City of Sydney (both areas were shown on maps to respondents). Those answers are compared to the data from the ABS census of 2016 (Australian Bureau of Statistics, n.d.).

Respondents were then asked to estimate the percentage of the Greater Sydney Area jobs they thought they could reach in 30 minutes from their home by walking, push bike, public transport and car. The same question was asked 


\begin{tabular}{|c|c|c|}
\hline & Sample & Sydney High Density Area \\
\hline Gender & $\begin{array}{l}\text { Women: } 55 \% \\
\text { Men: } 44.5 \% \\
\text { Prefer not to say: } 0.5 \%\end{array}$ & $\begin{array}{l}\text { Women: } 50.7 \%^{*} \\
\text { Men: } 49.3 \%^{*}\end{array}$ \\
\hline Age & $\begin{array}{l}15-19: 7 \% \\
20-29: 34 \% \\
30-39: 21 \% \\
40-49: 16 \% \\
50-59: 15 \% \\
60-69: 6 \% \\
70+: 1 \% \\
\text { Not stated: } 1 \%\end{array}$ & $\begin{array}{l}15-19: 6 \% \\
20-29: 23 \% \\
30-39: 22 \% \\
40-49: 16 \% \\
50-59: 13 \% \\
60-69: 10 \% \\
70+: 11 \%\end{array}$ \\
\hline Employment & $\begin{array}{l}\text { Work: } 65 \% \\
\text { Work \& Student: } 12 \% \\
\text { Student: } 17 \% \\
\text { Unemployed: } 4 \% \\
\text { Other: } 3 \%\end{array}$ & $\begin{array}{l}\text { Work: } 60 \% \\
\text { Unemployed: } 4 \% \\
\text { Other: } 36 \%\end{array}$ \\
\hline Household type & $\begin{array}{l}\text { Couple without children: } 23 \% \\
\text { Couple or single parent family: } 33 \% \\
\text { Lone person: } 15 \% \\
\text { Group household: } 23 \% \\
\text { Other: } 1 \%\end{array}$ & $\begin{array}{l}\text { Couple without children: } 25 \% \\
\text { Couple or single parent family: } 36 \% \\
\text { Lone person: } 22 \% \\
\text { Group household: } 7 \% \\
\text { Other: } 9 \%\end{array}$ \\
\hline Household income & $\begin{array}{l}\text { No income: } 6 \% \\
\$ 1-\$ 750: 14 \% \\
\$ 751-\$ 1,500: 17 \% \\
\$ 1,501-\$ 2,500: 19 \% \\
\$ 2,501-\$ 5,000: 30 \% \\
\$ 5,000 \text { or more: } 15 \%\end{array}$ & $\begin{array}{l}\$ 0-\$ 649: 15 \% \\
\$ 650-\$ 2499: 45 \% \\
\$ 2500-\$ 4999: 24 \% \\
\$ 5000+: 7 \% \\
\text { Not applicable / Not stated: 8\% }\end{array}$ \\
\hline Transport mode & $\begin{array}{l}\text { Walk: } 10 \% \\
\text { Push bike: } 26 \% \\
\text { E-Bike: } 8 \% \\
\text { Car: } 10 \% \\
\text { Public transport: } 45 \% \\
\text { Motorbike: } 1 \%\end{array}$ & $\begin{array}{l}\text { Walked only: } 8 \% \\
\text { Bike: } 1 \% \\
\text { Car as a driver: } 39 \% \\
\text { Public Transport: } 33 \% \\
\text { Motorbike / Scooter: } 1 \% \\
\text { Other / Didn't go to work: } 17 \%\end{array}$ \\
\hline
\end{tabular}

for the percentage of the City of Sydney jobs. Their answers are compared to our estimate of the percentage of jobs they could actually reach based on the spatial distribution of jobs given by the ABS Census of 2016, and the travel times given by Open TripPlanner using a walk speed of $4.8 \mathrm{~km} / \mathrm{h}$, a bike speed of $18 \mathrm{~km} / \mathrm{h}$ and network as described below, public transport travel times from published schedules in GTFS from Wednesday, February 05, 2020 and automobile travel times from CompassIo $T$. The travel time are calculated starting from the nearest cross-intersection of the respondent's home.

To assess the bikability of a road, a key factor is the separation with motorized traffic, as cycling collisions are mostly caused by interaction with motorized vehicles (Manton et al. 2016). Speed and density of traffic should also be considered. Cyclists themselves have different tolerance for roads requiring traveling in automobile traffic and needing skills to navigate safely (Murphy and Owen 2019). All the roads that are authorized to cyclists might not be considered as bikable to everyone. To take these considerations into account, cycling access to jobs was first calculated using the entire network and secondly 


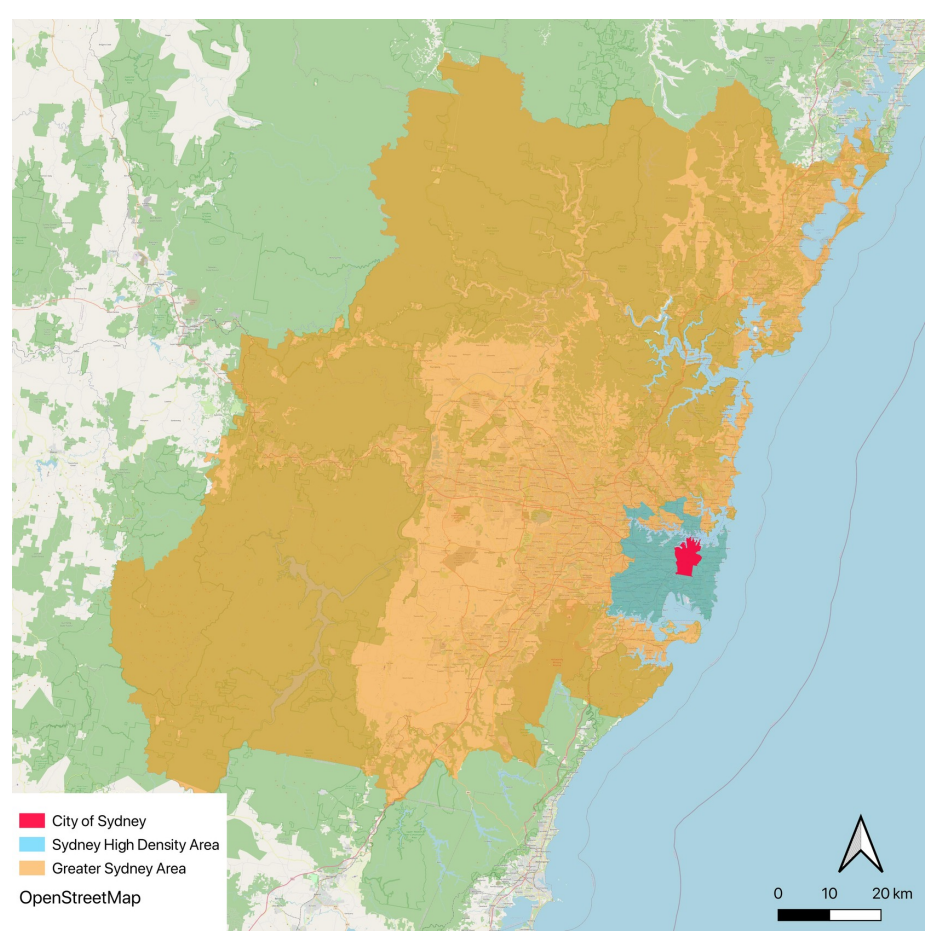

Figure 1: Sydney areas

using a low stress network. The low stress network was built upon the OpenStreetMap classified network, and contains only the "Paths separated from traffic" and the "low traffic streets".

To assess the perception of travel times, respondents were asked to estimate travel times on the trip they make most often if they were to do it by walking, by push-bike, by e-bike, and by public transport. The travel times for walk, push bike, car and public transport are compared to Google Maps estimates. As there is no available travel time for e-bikes on Google Maps, they were estimated using average e-bike speeds and the push bikes travel distances. The average speed on e-bikes greatly depend on where the trips are performed (Lopez et al. 2017). Lopez find an average speed of $16.7 \mathrm{~km} / \mathrm{h}$ and identifies two "speed-groups": one around $10 \mathrm{~km} / \mathrm{h}$ and one between 24 and $30 \mathrm{~km} / \mathrm{h}$. These groups could be related to the trip environment, as trips in city's centers have lower average speed because of traffic lights and congestion (Lopez et al. 2017). Trips from the respondents of the survey are in the Greater Sydney Area. It is an urban and suburban environment so the average speed will be higher than in a city center described by Lopez. Therefore, it seems reasonable to use the average speed of $16.7 \mathrm{~km} / \mathrm{h}$ for e-bikes in the City of Sydney. Some of the respondents answers were excluded according the following rules:

- Respondents with a missing estimate of travel time either for walk, push bike, public transport or car are excluded. This is done to compare the answers of an identical sample for these four transport modes. 
- Answers where only the estimate of travel time for E-bikes was missing are kept. As detailed previously, for this mode, the actual travel time was obtained with a different method, that is why it can be considered separately from the others and have a different sample.

- Respondents whose estimate for travel time is more than 15 times greater than the actual travel time either for walk, push bike, public transport or car are excluded. They are considered to be inconsistent.

- Respondents were asked to estimate the travel time for their own transport mode and to give their departure and arrival times. If the ratio of the estimated travel time and the calculated travel time is greater than two (or less than $1 / 2$ ), the respondents were excluded.

After this filtering, the sample comprises 185 persons, of whom 18 walk, 47 use a push bike, 15 use an e-bike, 18 use a car, 85 use public transport, and 2 use a motorbike.

\section{Findings}

\section{Perception of access to jobs}

According to the Australian Bureau of Statistics, there were 2,209,296 workers in the Greater Sydney Area in 2016 (Australian Bureau of Statistics, n.d.). The cumulative curve in figure 2 shows the estimates of the respondents. First of all, there is a visible tendency to choose rounded numbers. Estimate are globally very good as the average of the respondent's estimates is 2,001,676 and the median is $2,200,000$. If we consider only the respondents in the high density area (figure 1), the mean estimate of the number of jobs in Greater Sydney Area is 2,296,104 and the median is 2,400,000. The estimate from respondents living outside of the high density area are respectively 1,941,304 and 1,900,000. A t-test performed between those two groups indicates that the difference between means estimates can be considered negligible (Aoustin 2020). Average estimates depending on the transport mode used by the respondents were also compared, but no significant differences were found (Aoustin 2020).

For the City of Sydney proper, the number of jobs were greatly overestimated. The Australian Bureau of Statistics reports 498,422 jobs in the City of Sydney in 2016 (Australian Bureau of Statistics, n.d.), but the average estimate of the respondents is 980,905 and the median estimate is 900,000 . The average and median estimates for the number of jobs in the City of Sydney are respectively 988,889 and 900,000 for the high density residents, 1,015,217 and 900,000 for the others. A t-test indicates that the difference between means estimates of these two groups is also negligible. There is also no significant difference between the estimates of the respondents depending on the transport mode they use. 


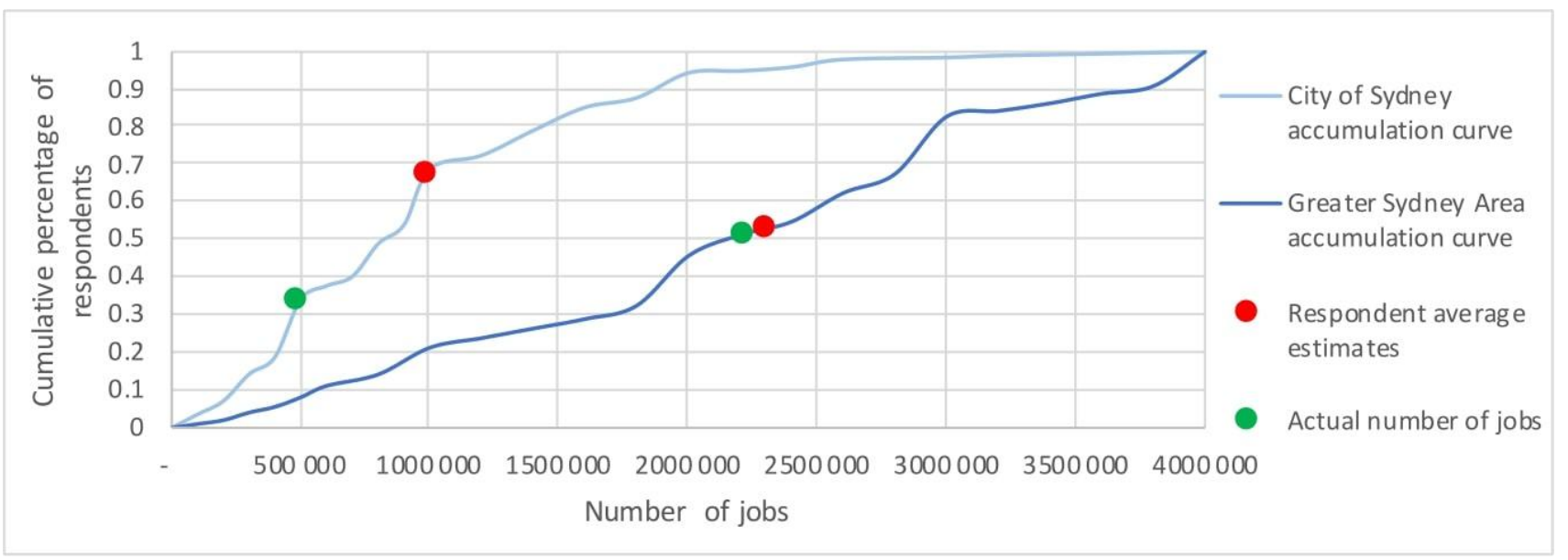

Figure 2: Cumulative distribution curve of the respondents estimates of the number of job in Greater Sydney Area and in the City of Sydney

Therefore, regardless of place of residence and transport mode used, respondents overestimated the attraction of the City of Sydney. This corroborates Hypothesis 1, but doesn't support Hypothesis 2.

When asked what percentage of the jobs they thought they could reach, respondents widely overestimated the access to jobs in Greater Sydney Area. Most (87\%) of them overestimated the walking access, $66 \%$ the cycling access and $91 \%$ the public transport access. Only the car access was underestimated with only $41 \%$ of people making overestimates. For the access to the City of Sydney's jobs, the overestimate is lower: $62 \%$ of the respondents overestimated the walking access, $42 \%$ the cycling access, $72 \%$ the public transport access and $22 \%$ the car access.

The average access given by the respondents $\left(A_{r}\right)$ was divided by the average access we calculated $\left(A_{c}\right)$ (equation 1 ). The value of $R_{1}$ for each transport mode is given in table 2 .

$$
R_{1}=\frac{A_{r}}{A_{c}}
$$

The overestimate is much less significant for bicycle access. According to the respondents, the car is the transport mode with the best access, followed by public transport, push bikes and finally walking. According to the calculated job access, the order is: Car, push bike, push bike with the low stress network, public transport, and walking. As train, buses, metros and ferry are usually faster than push bikes, their users can usually reach more distant points in shorter time. However, their time maps are discontinuous. On the other hand, you can't reach points as far by bike, but the time map for this mode is continuous. They might have overestimated the overall average speed of public transport, in particular by underestimating the time spent in intermediate phases outside the main mode of transport (time needed to get to the station, to make a change, waiting time, etc.). They might also have underestimated 
Table 2: Number of jobs accessible estimated by respondents $\left(A_{r}\right)$, value calculated by researchers $\left(A_{c}\right)$ for each transport mode estimated and comparison ratio $\left(R_{1}=\frac{A_{r}}{A_{c}}\right)$

\begin{tabular}{lllll}
\hline Region & Transport mode & $\begin{array}{l}\text { Respondents average } \\
\text { estimates }\left(A_{r}\right)\end{array}$ & $\begin{array}{l}\text { Calculated access } \\
\left(A_{c}\right)\end{array}$ & $\begin{array}{l}\text { Ratio: } \\
R_{1}=\frac{A_{r}}{A_{c}}\end{array}$ \\
\hline & Walk & $13 \%$ & $3 \%$ & 2.12 \\
& Push bike (all network) & $26 \%$ & $17 \%$ & 0.80 \\
Greater Sydney & Push bike (low stress & - & $12 \%$ & 1.05 \\
Area & network) & & & 1.72 \\
& Public transport & $36 \%$ & $9 \%$ & 0.65 \\
\hline & Car & $44 \%$ & $49 \%$ & 4.53 \\
& Walk & $22 \%$ & $10 \%$ & 1.53 \\
Pity of Sydney bike (all network) & $41 \%$ & $52 \%$ & 2.16 \\
& Push bike (low stress & - & $39 \%$ & 4.04 \\
\end{tabular}

the discontinuity of the time maps accessible by public transport, by visualising the furthest points they could reach in 30 minutes, but forgetting that many intermediate areas were inaccessible to them in such time. Therefore, respondents have significantly overestimated the access by public transport compared to cycling access, which corroborates hypothesis 3 . Car access was underestimated. Respondents who overestimate the access of a transport mode compared to the others, will probably will be more inclined to use the former (Owen and Levinson 2015).

\section{Perception of travel times}

Travel time estimated by the respondents $\left(T_{r}\right)$ is compared to the travel times estimated by Google Maps $\left(T_{G}\right)$ using an accuracy ratio (equation 2). Average and standard deviation of this ratio are in table 3 , for every mode estimated, depending on the mode used by the respondent.

$$
R_{2}=\frac{T_{r}}{T_{G}}
$$

The travel times were mostly overestimated, as the global average accuracy ratio is 1.36 . This overestimate is especially significant for car travel times, as they have the highest average overestimate (1.79), with the highest standard deviation (0.99). This has several explanations: first, some stages of the journey are not taken into account by Google Maps: at the start, the time to get to your car, to get out of your parking space, and at the end, the time to find a parking place, to park, and to reach your final destination. If the trip is short, these steps will have a very significant impact on the total travel time compared to Google Maps. Then there is the car journey itself, which is subject to the uncertainties of traffic and congestion. Respondents may overestimate travel time by considering the worst case scenario as a precautionary measure. Furthermore, travel times on Google Maps are based on historical traffic data. 
Table 3: Average and (standard deviation) of the accuracy ratio $R_{2}=\frac{T_{r}}{T_{G}}$ of travel times, for every mode estimated, depending on the mode used by the respondent

\begin{tabular}{|c|c|c|c|c|c|c|c|}
\hline $\begin{array}{l}\text { Transport } \\
\text { mode } \\
\text { estimated } \\
\text { Transport } \\
\text { mode used }\end{array}$ & Walk & Push bike & E-bike & $\begin{array}{l}\text { Public } \\
\text { transport }\end{array}$ & Car & Total & $\begin{array}{l}\text { Total } \\
\text { without the } \\
\text { mode used } \\
\text { by the } \\
\text { respondent }\end{array}$ \\
\hline Walk & $1.36(0.62)$ & $2.09(1.50)$ & $1.71(0.95)$ & $2.20(1.22)$ & $2.55(1.63)$ & $1.98(1.28)$ & $2.14(1.35)$ \\
\hline Push bike & $0.98(0.34)$ & $1.10(0.41)$ & $0.90(0.34)$ & $1.36(0.57)$ & $1.76(0.63)$ & $1.22(0.56)$ & $1.26(0.59)$ \\
\hline E-bike & $1.11(0.45)$ & $1.37(0.49)$ & $1.10(0.56)$ & $1.42(0.64)$ & $1.75(0.74)$ & $1.35(0.61)$ & $1.41(0.62)$ \\
\hline $\begin{array}{l}\text { Public } \\
\text { transport }\end{array}$ & $1.08(1.09)$ & $1.41(0.74)$ & $1.18(0.69)$ & $1.16(0.55)$ & $1.68(1.02)$ & $1.30(0.64)$ & $1.34(0.93)$ \\
\hline Car & $1.01(0.42)$ & $1.46(0.62)$ & $1.29(0.56)$ & $1.44(0.50)$ & $1.74(0.75)$ & $1.39(0.62)$ & $1.30(0.55)$ \\
\hline Motorbike* & $1.09(1.03)^{*}$ & $1.15(0.81)^{*}$ & $1.18(1.06)^{*}$ & $1.29(0.73)^{*}$ & $0.92(0.33)^{*}$ & $1.12(0.87)^{*}$ & $1.12(0.87)^{*}$ \\
\hline Total & $1.08(0.81)$ & $1.40(0.79)$ & $1.17(0.66)$ & $1.36(0.71)$ & $1.79(0.99)$ & $1.36(0.84)$ & $1.38(0.81)$ \\
\hline
\end{tabular}

* non- representative

The Google Maps travel times used here were calculated on the 20th of May 2020. At this point, they were influenced by the recent downturn in traffic due to COVID-19. However it should be noted that Google Maps may also bias their travel time upward so travelers will not be upset when the trip is longer than the underlying estimate and be pleased when it is lower than reported. A comparison of different travel time sources for Sydney is given in $\mathrm{Wu}(2019)$.

If we examine travel time estimates according to the mode of transport used by respondents, we can see that those who walk are the furthest away from Google Maps travel time, with an average $R_{2}$ of 1.98 and a standard deviation of 1.28. They overestimated all modes of transport, including their own (1.36 average $R_{2}$ and 0.62 standard deviation), and especially car journeys ( 2.55 mean ratio estimate and 1.63 standard deviation). The additional steps to be added to the time estimated by Google Maps have a stronger impact on the trips of these respondents, as they have the shortest trips ( $1.5 \mathrm{~km}$ average). For these trips, only a few minutes difference in the estimates can have a great influence on the accuracy ratio.

When estimating their own transport mode travel times, car users estimates differ the most from Google Maps (1.74 mean ratio estimate and 0.75 standard deviation). This is in line with what has been said above on the uncertainty of travel time, the impact of COVID-19, the importance of the stages at the beginning and end of the trip for this mode.

Finally, except for the car users, the overestimate was higher for transport modes that respondents did not use than for their own transport mode, which corroborates hypothesis 4. Pedestrians and public transport users had the most difficulty estimating travel times for the other modes as they have the highest standard deviations. For people who walk, this is consistent with the comments made earlier on the influence of distance on travel time estimates. 
For public transport users, this shows that they have more difficulty estimating travel times for other modes. Indeed, it is a transport mode that doesn't require attention to the road during the trip, but rather to the number of stations, changes, etc. This information is obtained on maps that differ from those used for the other modes, resulting in a different visualization of the environment. We thus corroborate hypothesis 5 .

\section{Acknowledgments}

We would like to thank Prof. Vincent Kaufmann and Marc-Edouard Schultheiss for their contribution by supervising the Master's Thesis on which this article is based. Thank you to Hao Wu for his help on the calculation of access to jobs. We would also like to thank the participants of the survey for their responses.

Submitted: January 17, 2021 AEDT, Accepted: February 01, 2021 AEDT

This is an open-access article distributed under the terms of the Creative Commons Attribution 4.0 International License (CCBY-SA-4.0). View this license's legal deed at https://creativecommons.org/ licenses/by-sa/4.0 and legal code at https://creativecommons.org/licenses/by-sa/4.0/legalcode for more information. 


\section{REFERENCES}

Aoustin, L. 2020. “The Perception of Access in Sydney.” Technical report.

Australian Bureau of Statistics. n.d. “2016 Australian Census.” https://www.abs.gov.au/ websitedbs/censushome.nsf/home/2016.

Hansen, W. G. 1959. "How Accessibility Shapes Land Use." Journal of the American Institute of Planners 25 (2): 73-76.

Lopez, Angel J, Paola Astegiano, Sidharta Gautama, Daniel Ochoa, Chris MJ Tampère, and Carolien Beckx. 2017. "Unveiling E-Bike Potential for Commuting Trips from GPS Traces." ISPRS International Journal of Geo-Information 6 (7): 190.

Lynch, K. 1960. The Image of the City. Vol. 11. MIT press.

Manton, R., H. Rau, F. Fahy, J. Sheahan, and E. Clifford. 2016. "Using Mental Mapping to Unpack Perceived Cycling Risk.” Accident Analysis E̋ Prevention 88: 138-49.

Murphy, Brendan, and Andrew Owen. 2019. "Implementing Low-Stress Bicycle Routing in National Accessibility Evaluation.” Transportation Research Record 2673 (5): 240-49.

Owen, Andrew, and David M Levinson. 2015. "Modeling the Commute Mode Share of Transit Using Continuous Accessibility to Jobs." Transportation Research Part A: Policy and Practice 74: 110-22.

Wu, H. 2019. “Comparing Google Maps and Uber Movement Travel Time Data.” Transport Findings. 